\title{
ON STATISTICAL CONVERGENCE WITH RESPECT TO MEASURE
}

\author{
ÖMER KIŞI AND ERHAN GÜLER
}

\begin{abstract}
Several notions of convergence for subsets of metric spaces appear in the literature. In this paper, for real valued measurable functions defined on a measurable space $(X, \mathscr{M}, \mu)$, we obtain a statistical version of Lebesque's bounded convergence theorem (when $\mu(X)<\infty$ ) and examine the validity of the classical theorems of Measure Theory for statistical convergences.
\end{abstract}

Mathematics subject classification (2010): 40G15, 40A35.

Keywords and phrases: Statistical convergence, measurable function.

\section{REFERENCES}

[1] B. T. Bilalov, T. Y. NaZARova, Statistical convergence of functional sequences, Rocky Mountain J. Math. volume 45, number 5 (2015), 1413-1423.

[2] J. Connor, Two valued measures and summability, Analysis 10 (1990), 373-385.

[3] J. Connor, R-type summability methods, Cauchy criteria, P-sets and statistical convergence, Proc. Amer. Math. Soc. 115, (1992) 319-327.

[4] S. Dolecki, G. SalinetTi And R. J.-B. Wets, Convergence of functions: Equi-semicontinuity, International Institute For Applied Systems Analysis, Laxenburg, Austria, (1980).

[5] O. Duman, C. Orhan, $\mu$-statistically convergent function sequences, Czech. Math. J., 54, 129 (2004), 413-422.

[6] H. FAST, Sur la convergence statistique, Coll. Math., 2, (1951), 241-244.

[7] H. FEDERER, Geometric Measure Theory, Springer, New York, (1969).

[8] J. A. FRIDY, On statistical convergence, Analysis, 5 (1985), 301-313.

[9] S. R. SAdigova, T. Y. NAZARova, Statistical type Lebesgue and Riesz theorems, International Journal of Mathematical Analysis, 9, 34 (2015), 1669-1683.

[10] S. HARTMAN, Sur une familie singuliére d'ensembles de nombres naturels, Colloq. Math., 2 (1951), 245-248.

[11] M. Balcerzak, K. Dems, A. Komisarski, Statistical convergence and ideal convergence for sequences of functions, J. Math. Anal. Appl., 328, (2007), 715-729.

[12] M. BalcerzaK And K. Musial, Vitali Type Convergence Theorems for Banach Space Valued Integrals, Acta. Math. Sinica, English Ser., 29, 11 (2013), 2027-2036.

[13] I. P. NATANSON, Theory of functions of a real variable, 1955.

[14] C. Papachristodoulos, On convergence of sequences of measurable functions, $\mathrm{PhD}$ thesis, Department of Mathematics, University of Athens, Greece, 2009.

[15] N. Papanastassiou, On a new type of convergence of sequences of functions, Atti Sem. Math. Fis. Univ. Modena, 50, (2002), 355-368.

[16] T. SALAT, On statistically convergent sequences of real numbers, Math. Slovaca, 30 (1980), 139-150.

[17] I. J. Schoenberg, The integrability of certain functions and related summability methods, Amer. Math. Monthly, 6, (1959), 361-375.

[18] H. Steinhaus, Sur la convergence ordinarie et la convergence asymptotique, Colloq. Math. 2, (1951), 73-74. 